\title{
Rancang Bangun Modul Kontrol Simulator Refrigerasi Adsorpsi Berbasis Arduino dan Labview
}

\author{
Solehudin 1,2 , I Made Astina1,3 \\ 1Program Studi Teknik Mesin, FTMD, Institut Teknologi Bandung, Jl Ganesha 10, Bandung \\ ²soldien.pm/@gmail.com, ${ }^{3}$ astina@ftmd.itb.ac.id
}

\begin{abstract}
Abstrak
Refrigerasi Adsorpsi adalah mesin refrigerasi yang memanfaatkan fenomena adsorpsi-desorpsi untuk menaikkan tekanan refrigeran. Mesin ini menggunakan bed adsorpsi sebagai pengganti kompresor. Berbeda dengan kompresor yang membutuhkan sumber energi listrik, bed adsorpsi membutuhkan pasokan panas untuk beroperasi. Sumber panas yang diperlukan dapat berasal dari berbagai panas buang yang belum termanfaatkan. Oleh karena itu mesin refrigerasi ini dapat dijadikan sebagai salah satu solusi penghematan energi sekaligus mengurangi pemanasan global.

Seiring perkembangan mesin refrigerasi adsorpsi, teknologi kontrol juga perlu dikembangkan untuk mengoptimasi kinerjanya. Pada paper ini, perancangan dan pembuatan sistem kontrol akan dibahas untuk menyimulasikan mesin refrigerasi adsorpsi dua bed. Sistem kontrol ini berbasiskan arduino yang terintegrasi dengan perangkat lunak labview sebagai sarana interaksi antara sistem dan pengguna. Sistem ini mampu menyimulasikan mesin refrigerasi adsorpsi melalui pengontrolan buka tutup katup dan pemanasan dan pendinginan kedua. Pada simulasi kontrol mesin refrigerasi ini digunakan thermoelectric cooler (TEC) sebagai pengganti sumber panas untuk memanaskan sekaligus mendinginkan.
\end{abstract}

Kata Kunci: Refrigerasi adsorpsi, thermoelectric cooler, arduino, labview, katup selenoid

\section{Pendahuluan}

Mesin refrigerasi adsorpsi dapat menjadi solusi penghematan energi. Hal ini dikarenakan mesin refrigerasi jenis ini tidak membutuhkan banyak energi listrik untuk beroperasi. Energi listrik yang biasa digunakan untuk menggerakkan kompresor, digantikan oleh energi panas untuk memanaskan bed adsorpsi. Energi panas yang diperlukan dapat berasal dari sumber panas buang yang belum termanfaatkan. Menimbang keunggulan mesin refrigerasi adsorpsi, penelitian lebih lanjut perlu dilakukan termasuk pengembangan teknologi kontrol penunjang kinerjanya.

Untuk beroperasi secara kontinyu sebuah bed adsorpsi harus dipanaskan dan didinginkan secara bergantian dan periodik. Penggunaan 2 bed adsorpsi pada mesin refrigerasi ini telah dikembangkan oleh Jati Purnomo[2] dan pengujiannya menggunakan pasangan karbon aktif dan R-134a. Selain itu arah aliran refrigeran pada mesin refrigerasi adsorpsi juga harus diatur dengan cara mengatur buka tutup katup. Pada simulator kontrol mesin refrigerasi adsorpsi ini, balok alumunium digunakan sebagai pengganti bed adsorpsi dan TEC sebagai pengganti sumber panas.

Penggunaan TEC pada mesin refrigerasi adsorpsi juga telah dilakukan oleh Chua dkk[2]. Mesin refrigerasi yang mereka kembangkan hanya menggunakan 1 kondensor yang terpisah dari efek pendinginan TEC, sedangkan simulator yang dikembangkan dalam penelitian ini menggunakan 2 kondensor yang masing-masing terhubung dengan bed adsorpsi. Dengan demikian pendinginan kondensor dapat mengambil efek dingin dari TEC.

\section{Prinsip Kerja Refrigerasi Adsorpsi}

Untuk menjelaskan prinsip kerja mesin refrigerasi adsorpsi, akan lebih mudah terlebih dahulu menjelaskan prinsip kerja mesin kompresi uap yang umumnya digunakan mesin-mesin refrigerasi saat ini di masyarakat. Mesin refrigerasi kompresi uap terdiri dari empat komponen utama, yaitu: kompresor, kondensor, katup ekspansi dan evaporator. Fluida pendingin (refrigeran) akan mengalir melewati komponen-komponen tersebut sehingga membentuk siklus refrigerasi. Gambar 1 memperlihatkan skema dan proses-proses siklus refrigerasi kompresi uap.

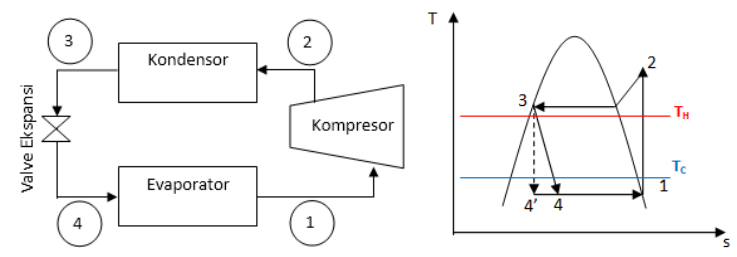

Gambar 1: skema mesin refrigerasi kompresi uap

Dari skema di atas terlihat bahwa proses 1 - 2 merupakan kompresi secara isentropis (entropi konstan) sehingga tekanan dan temperatur refrigeran meningkat. Refrigeran yang bertemperatur tinggi ini dialirkan ke kondensor dan akibat temperaturnya lebih tinggi dari lingkungan, kalor mengalir dari refrigeran ke lingkungan. Proses pelepasan kalor ini 
menyebabkan refrigeran terkondensasi (proses 2 3). Pada proses 3 - 4, refrigeran melalui katup ekspansi sehingga tekanan dan temperaturnya turun dan selanjutnya refrigeran mengalir menuju evaporator. Karena temperatur refrigeran di evaporator lebih rendah dari lingkungan, maka terjadi kalor masuk ke dalam evaporator. Proses ini menyebabkan refrigeran menguap. Selanjutnya refrigeran masuk kembali ke kompresor dan seterusnya membentuk siklus refrigerasi.

Secara praktis mesin refrigerasi adsorpsi adalah mesin refrigerasi yang menggantikan kompresor dengan bed adsorpsi sebagai penaik tekanan. Perbedaan kompresor dengan bed adsorpsi dalam menaikan tekanan refrigeran dapat dijelaskan dengan gambar 2 .

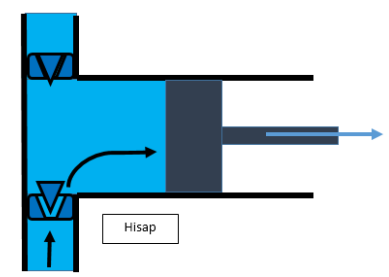

(a)

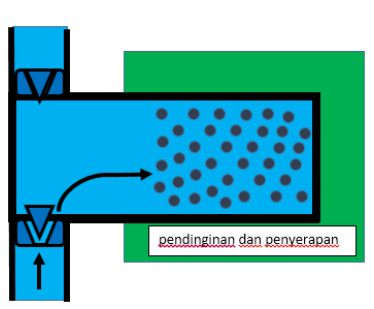

(c)

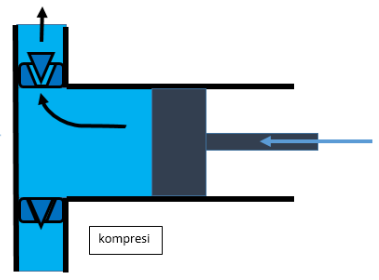

(b)

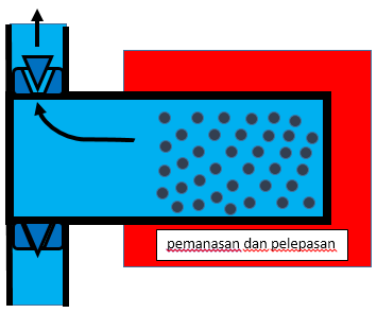

(d)
Gambar 2: perbedaan prinsip kerja kompresor dengan bed adsorpsi

Gambar 2 menunjukkan perbedaan prinsip kerja antara kompresor dengan bed adsorpsi dalam menaikkan tekanan refrigeran. Gambar 2(a) dan 2(b) adalah skema kompresor torak yang memanfaatkan fenomena hisap-kompresi untuk menaikkan tekanan. Gambar 2(c) dan 2(d) adalah skema bed adsorpsi yang memanfaatkan fenomena desorpsi-adsorpsi oleh suatu zat pengadsorpsi dalam operasinya. Berbeda dengan kompresor yang menggunakan kerja mekanik untuk beroperasi, pada bed adsorpsi digunakan sumber panas dan dingin untuk menaikkan tekanan. Ketika bed adsorpsi didinginkan, maka refrigeran akan terserap oleh suatu padatan adsorben dan masuk dalam pori-pori permukaannya. Kemudian saat bed adsorpsi dipanaskan, maka refrigeran yang terserap oleh adsorben terlepas dan keluar dari bed adsorpsi dengan tekanan yang tinggi. Proses pemanasan dan pendinginan bed adsorpsi harus dilakukan secara bergantian dan periodik agar proses kompresi dapat berlangsung secara kontinyu. Dalam aplikasinya sumber panas ini dapat berasal dari panas buang yang belum termanfaatkan, sedangkan pendinginan dapat dilakukan dengan udara sekitar atau dengan air pendingin.

\section{Rancangan Simulator Refrigerasi Adsorpsi}

Simulator mesin refrigerasi adsorpsi yang telah dirancang terdiri dari dua buah bed, dua kondensor, katup ekspansi dan evaporator. Sebagai pengganti sumber panas, pada simulator ini digunakan thermo electric cooler (TEC). Skema dan miniatur simulator yang telah dirancang diberikan pada gambar 3 .
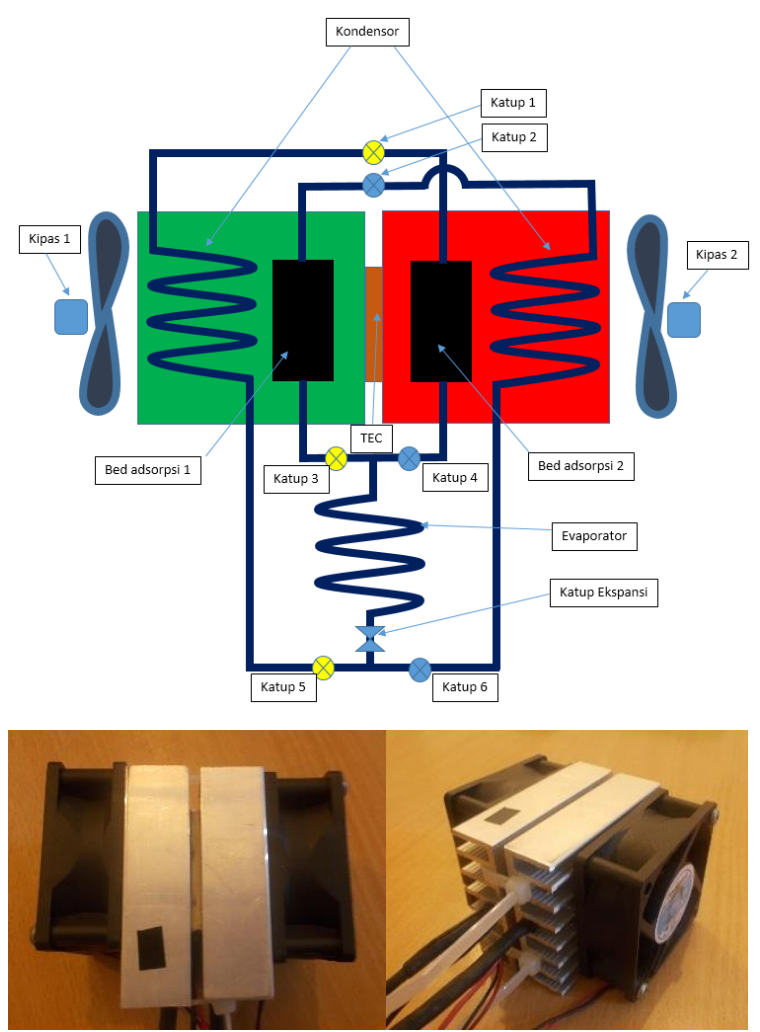

Gambar 3: skema dan miniatur simulator mesin refrigerasi adsorpsi

Prinsip kerja kompresi mesin refrigerasi ini yaitu dengan pemanfaatan fenomena adsorpsi-desorpsi. Pada saat temperatur lingkungan bed dingin maka adsorben di dalam bed akan menyerap refrigeran sedangkan pada saat temperatur bed panas maka refrigeran akan terlepas dari adsorben. Proses pemanasan dan pendinginan bed dilakukan oleh modul TEC yang terpasang diantara kedua bed. 
Ketika arus DC diberikan ke modul TEC maka sebuah bed akan menjadi panas sedangkan bed yang lain akan menjadi dingin sehingga terjadi aliran refrigeran dari bed panas (desorpsi) ke bed dingin (adsorpsi). Apabila arah arus DC dibalik, maka pemanasan dan pendinginan yang terjadi berbeda dan temperaturnya terbalik akibatnya arah aliran refrigeran juga terbalik. Aliran refrigeran harus mengikuti siklus refrigerasi sehingga katup selenoid digunakan untuk mengatur arah aliran refrigeran. Siklus refrigerasi adsorpsi berawal dari desorber menuju kondensor, dan selanjutnya melewati katup ekspansi, dan kemudian evaporator dan akhirnya masuk ke adsorber. Setelah penyerapan absorber maksimum, kemudian adsorber dipanaskan lagi sehingga proses desorpsi berlangsung dan demikian seterusnya proses-proses tersebut membentuk siklus refrigerasi.

\section{Model Matematika}

Pemodelan matematika digunakan untuk membantu analisis kontrol yang dilakukan. Parameter kontrol berupa pengaturan temperatur pemanasan dan pendinginan bed serta buka tutup katup. Agar pengaturan buka tutup katup mudah dapat dilakukan, pin digital output arduino digunakan dan dihubungkan dengan rangkaian kontrol relay. Sedangkan pengaturan temperatur dilakukan dengan kontrol on/off TEC dan kecepatan kipas diatur melalui pin pwm arduino. Oleh karena itu pemodelan matematika perlu dilakukan. Hubungan-hubungan empirik dari karakteristik TEC telah dibahas pada pustaka [3].

\subsection{Persamaan energi sisi dingin TEC}

Panas yang dikeluarkan pompa kalor pada sisi dingin TEC ideal dihitung dengan persamaan Seeback yang ditunjukkan pada persamaan (1).

$$
Q_{s b}=2 N \alpha I T c
$$

Karena material TEC mempunyai hambatan dalam menghasilkan kalor Joule. Kalor Joule ini diasumsikan setengahnya ke sisi dingin dan setengahnya lagi ke sisi panas. Besar nilai kalor Joule dihitung dengan persamaan (2).

$$
Q_{j}=2 N I^{2} p / G
$$

Perbedaan temperatur antara kedua sisi TEC saat beroperasi menyebabkan terjadi perpindahan panas konduksi yang besarnya dapat dihitung dengan persamaan (3).

$$
Q c d=2 N \mathrm{k}(T h-T c) G
$$

Untuk perpindahan panas total pada sisi dingin dapat diestimasi dengan persamaan (4).

$$
\begin{aligned}
Q_{c}=Q_{s b}-0,5 Q_{j}-Q_{c d} \\
\quad=2 N\left(\alpha I T_{c}-I^{2} p / 2 G-k \Delta T\right)
\end{aligned}
$$

Persamaan (4) merupakan persamaan standar untuk kinerja termal dari modul TEC. Untuk penyederhanaan, $S M, R M$, dan $K M$ didefinisikan pada persamaan-persamaan (5) - (7). Dengan parameter ini, karakteristik TEC dapat dinterpretasikan.

$$
\begin{aligned}
& S M=2 \alpha N \\
& R M=2 p N / G \\
& K M=2 N k G
\end{aligned}
$$

Dengan definisi-definisi parameter tersebut, persamaan (4) dapat dituliskan menjadi persamaan (8).

$$
Q_{c}=S M T C I-0,5 I^{2} R M-K M \Delta T
$$

Dari persamaan (8) dapat terlihat bahwa besar $Q_{c}$ merupakan fungsi kuadratik dari $I$. Hal ini menunjukkan terdapat nilai $I$ optimum untuk memperoleh $Q_{c}$ terbesar. Selain itu, nilai $Q_{c}$ juga bergantung pada nilai $\Delta T$ dan $T_{\mathrm{C}}$ sehingga nilai $Q_{c}$ tidak dapat diatur dengan hanya mengatur nilai $I$. Dengan kata lain nilai $T c$ dan $\Delta T$ tidak dapat diatur dengan hanya mengatur nilai $I$.

\subsection{Persamaan energi sisi panas TEC}

Tegangan pada modul TEC dapat dirumuskan sebagaimana diberikan pada persamaan (9).

$$
V=I R M+S M(T h-T c)
$$

Besar energi yang dikonsumsi modul TEC dapat diestimasi dengan persamaan (10).

$$
P=V I=I^{2} R M+S M I\left(T h-T_{c}\right)
$$

Dengan menggambungkan persamaan (8) dan (10) ke hukum kekekalan energi, maka diperoleh persamaan $Q h$ yang diberikan pada persamaan (11).

$$
\begin{aligned}
Q_{h} & =Q_{c}+P \\
& =S M T h I+0,5 I^{2} R M-K M \Delta T
\end{aligned}
$$

Persamaan (11) ini mengonfirmasikan bahwa untuk mengatur $T_{h}$ dan $\Delta T$ tidak cukup dengan hanya mengatur $I$.

\subsection{Pengaruh kecepatan udara}

Untuk mengatur $T_{c}$ dan $T_{h}$ tidak dapat dilakukan hanya dengan mengatur $I$. Oleh karena itu selain harus dapat mengatur $I$, pengontrol juga harus 
dapat mengontrol $Q$ c dan $Q$ h. Oleh karena itu pada simulator yang dikembangkan, kipas motor DC digunakan untuk membantu pengaturan temperatur. Perpindahan panas yang terjadi pada sisi luar bed merupakan perpindahan panas secara konveksi. Perpindahan panas konveksi telah dirumuskan pada hukum pendinginan Newton yang ditunjukkan pada persamaan (12)

$$
Q=h A \Delta T
$$

Dari pesamaan di atas terlihat bahwa besarnya nilai $\mathrm{h}$ akan mempengaruhi besarnya perpindahan panas $Q$ ataupun $\Delta T$ yang terjadi. Nilai $h$ tergantung pada berbagai kondisi. Salah satu kondisi yang mempengaruhi $h$ adalah kecepatan aliran fluida sekitar. Hubungan kecepatan dan nilai $h$ dirumuskan pada persamaan bilangan Nusselt dan Reynolds pada analogi Reynolds yang diberikan pada persamaan-persamaan (13) - (15).

$$
\begin{aligned}
& N u=f\left(X^{*}, \operatorname{Re}, \operatorname{Pr}\right)=h L / k \\
& R e=\rho \cdot u . L / \mu \\
& C_{f} \operatorname{Re} / 2=N u
\end{aligned}
$$

Dari analogi Reynolds tersebut dapat disimpulkan bahwa semakin besar nilai $u$ maka semakin besar nilai $h$ sehingga semakin besar juga nilai $Q$. Oleh karena itu, untuk membantu pengaturan $Q$ digunakan kipas.

Dari analisis perpindahan panas di atas dapat dipastikan bahwa pengaturan kedua bed adsorpsi dapat dilakukan dengan cara pengaturan on/off TEC dan putaran kedua kipas.

\section{Rancangan, Prototipe, dan Hasil Pengujian Modul Kontrol}

Modul kontrol simulator mesin refrigerasi adsorpsi yang telah dikembangkan terdiri dari arduino, modul relay, katup selenoid, TEC, kipas pendingin dan sensor temperatur LM35. Gambar 4 memberikan ilustrasi tentang rancangan modul kontrol simulator refrigerasi adsorpsi.

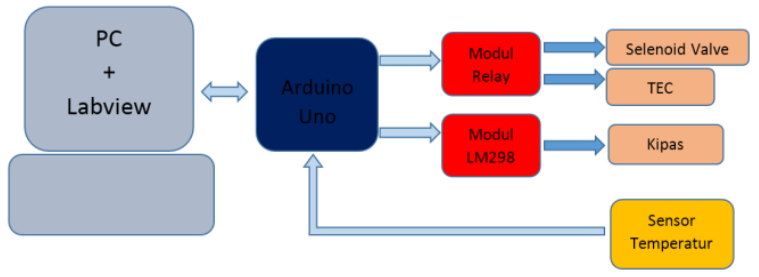

Gambar 4: sekema kontrol simulator mesin refrigerasi adsorpsi

Platform kontroller arduino yang digunakan pada modul kontrol ini bukan digunakan sebagai kontroller, melainkan hanya digunakan sebagai media penerjemah perintah dan pembaca data temperatur sensor. Pengontrolan dilakukan melalui perangkat lunak labview. Komunikasi antara labview dan arduino menggunakan komunikasi serial. Program yang dibuat pada arduino hanya membaca 3 byte perintah dan mengirimkan 4 byte data. 4 byte data yang dikirim oleh arduino mengandung informasi dua temperatur. 3 byte perintah yang diterima arduino terdiri dari perintah pengaturan katup, TEC, dan kipas. Bit 0 sampai bit 5 dari byte pertama digunakan untuk mengatur katup, sedangkan bit 6 dan bit 7 dari byte pertama digunakan untuk mengatur TEC. Dengan menggunakan rangkaian H-brigde Relay maka TEC dapat beroperasi off, positif atau negatif. Byte kedua dan ketiga digunakan sebagai perintah untuk mengatur kecepatan putar kipas. Pengaturan kecepatan putar kipas dilakukan dengan pin PWM arduino. Aliran data komunikasi antara arduino dan komponen lain dapat diilustrasikan pada gambar 5.

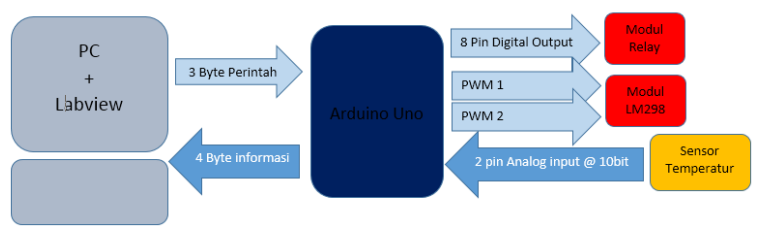

Gambar 5: sekema aliran perintah dan informasi

Pembuatan rangkaian listrik dari modul kontrol ini dilakukan dengan menggunakan perangkat lunak eagle. Desain rangkaian listrik yang telah dibuat diperlihatkan pada gambar 6 .

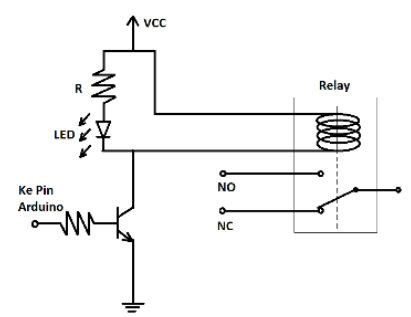

(a)

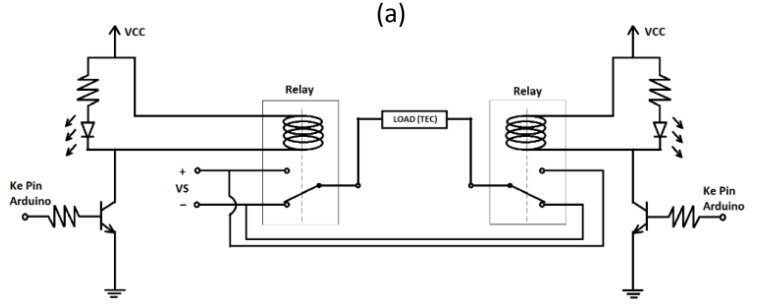

(b)

Gambar 6: Sekematik rangkaian listrik modul kontrol: (a) penggerak katup solenoid menggunakan relay dan transistor; (b) rangkaian H-Bridge relay untuk mengatur TEC 
Gambar 6 (a) menunjukkan rangkaian penggerak katup selenoid menggunakan relay. Alasan penggunaan relay pada rangkaian ini agar berbagai jenis tipe katup selenoid dapat digunakan.

Dalam pengerjaan modul kontrol ini diawali dengan pembuatan skema rangkaian, kemudian dilanjutkan dengan perancangan film PCB. Perancangan film PCB ini menggunakan perangkat lunak eagle. Selanjutnya pembuatan PCB dan pemasangan komponen dilakukan. Urutan pengerjaan modul kontrol ini dapat diperlihatkan pada gambar $7-9$.

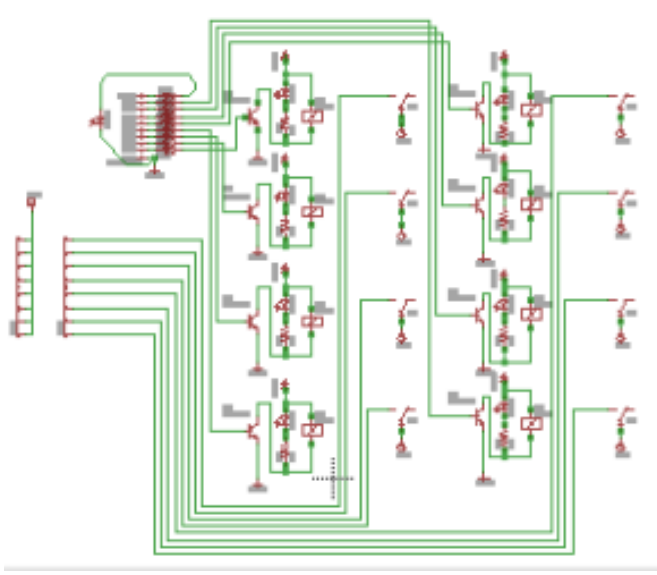

Gambar 7: skema rangkaian modul kontrol

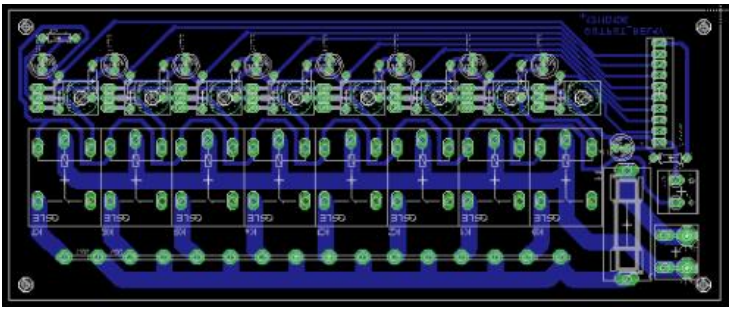

Gambar 8: tampilan film PCB modul kontrol

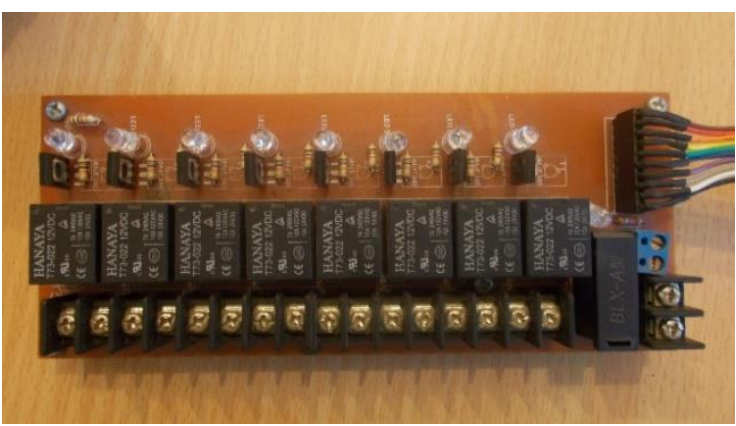

Gambar 9: modul kontrol yang telah dibuat

Dalam pengoperasian modul kontrol ini terdapat 3 mode yang dapat dipilih. Adapun ketiga mode tersebut adalah mode manual, timer dan auto. Pada mode manual, user secara langsung dapat mengendalikan katup, pengaturan pemanasan atau pendinginan oleh TEC dan juga pengaturan putaran kipas. Pada mode timer,user akan diminta untuk memasukan state meliputi konfigurasi bukatutup katup, penyalaan TEC dan pengaturan kecepatan kipas serta durasi waktu untuk tiap-tiap state. Pada mode auto, temperatur kedua bed adsorpsi dapat di atur. Pengaturan temperatur bed adsorpsi merupakan close loop control dengan menggunakan kontrol on/off modul TEC dan kontrol proporsional kecepatan putaran kipas. Diagram blok dari sistem kontrol temperatur kedua bed adsorpsi ditunjukkan pada gambar 10 .

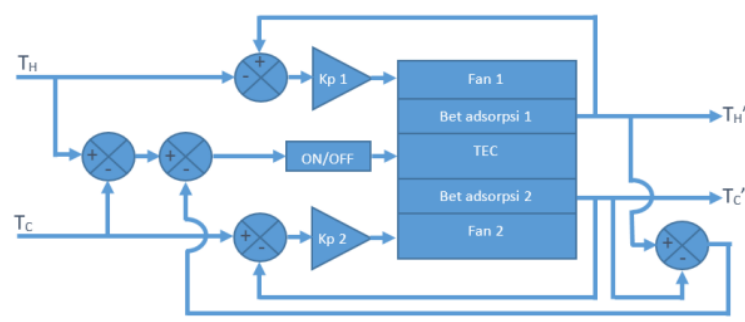

Gambar 10: diagram blok kontrol temperatur dua bet adsorpsi

Gambar 10 menunjukkan penggunaan kontrol on/off dan proporsional untuk mengatur temperatur bed adsorpsi. Dari diagram blok tersebut maka dapat dijelaskan bawha secara fisik TEC akan terus menyala selama selisih tempertaur yang terjadi masih lebih kecil dari selisih temperatur yang diinginkan. Kontrol proporsional pada kedua kipas merupakan proporsional mutlak yang hanya akan menguatkan saat nilai inputnya positif. Oleh karena itu, secara fisik kipas 1 akan berputar saat temperatur bed adsorpsi 1 lebih dari yang diinginkan, namun tetap diam selama temperatur yang terjadi di bawah temperatur set poin. Untuk kipas 2 juga hanya akan berputar saat temperatur bed adsorpsi 2 yang terjadi di bawah temperatur yang diinginkan.

Pada mode timer pengguna hanya perlu memasukan konfigurasi katup tiap-tiap state. Tabel 1 merepresentasikan konfigurasi state secara default.

Tabel 1: konfigurasi state pada mode timer

\begin{tabular}{|c|c|c|c|c|c|c|c|c|}
\hline \multirow{2}{*}{$\begin{array}{l}\text { Variabel } \\
\text { Kontrol }\end{array}$} & \multicolumn{8}{|c|}{ State } \\
\hline & 1 & 2 & 3 & 4 & 5 & 6 & 7 & 8 \\
\hline Katup1 & off & on & on & off & off & off & off & off \\
\hline Katup2 & off & off & off & off & off & on & on & off \\
\hline Katup3 & off & on & on & off & off & off & off & off \\
\hline Katup 4 & off & off & off & off & off & on & on & off \\
\hline Katup 5 & off & off & on & off & off & off & off & off \\
\hline Katup 6 & off & off & off & off & off & off & on & off \\
\hline TEC & $\mathrm{F}$ & $\mathrm{F}$ & $\mathrm{F}$ & off & $\mathrm{R}$ & $\mathrm{R}$ & $\mathrm{R}$ & off \\
\hline Kipas1(\%) & 0 & 50 & 100 & 100 & 0 & 0 & 0 & 100 \\
\hline Kipas2(\%) & 0 & 0 & 0 & 100 & 0 & 50 & 100 & 100 \\
\hline $\begin{array}{l}\text { Durasi } \\
\text { (menit) }\end{array}$ & 20 & 10 & 10 & 5 & 20 & 10 & 10 & 5 \\
\hline
\end{tabular}


Seperti diperlihatkan pada tabel 1, simbol $F$ mengartikan bahwa TEC diberikan tegangan positif, sedangkan simbol $\mathrm{R}$ ketika TEC diberikan tegangan negatif. Ketika TEC menerima tegangan positif, maka pemanasan terjadi pada bed adsorpsi 1 dan pendinginan pada bed adsorpsi 2 . Sebaliknya ketika TEC menerima tegangan negatif maka pendinginan terjadi pada bed adsorpsi 1 dan pemanasan pada bed adsorpsi 2 . State 1 adalah proses pemanasan dan pendinginan pada volum konstan. State 2 adalah proses desorpsi pada bed 1 dan adsorpsi pada bed 2. State 3 adalah proses yang menimbulkan efek pendinginan. State 4 adalah penetralan temperatur kedua bed. State 5 sampai dengan 8 merupakan kebalikan state 1 sampai dengan 4. Proses-proses tersebut diharapkan akan membentuk siklus refrigerasi adsorpsi ideal sebagai berikut seperti ditunjukkan pada gambar 11.

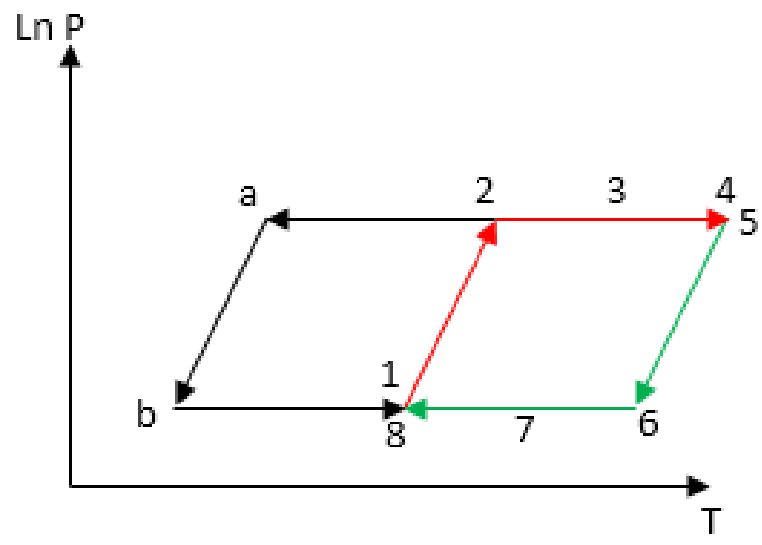

Gambar 11: diagram tekanan-temperatur refrigerasi adsorpsi ideal

Pembuatan program control dilakuakan dengan menggunakan perangkat lunak labview. Tampilantampilan front panel rancangan kontrol yang telah dibuat diperlihatkan pada gambar 12 - 15.

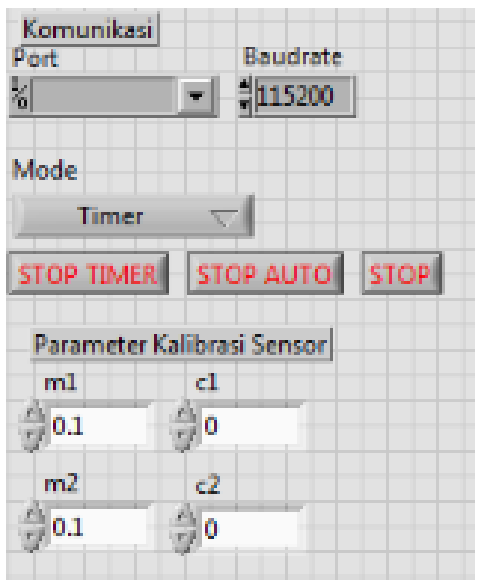

Gambar 12: tampilan seting parameter

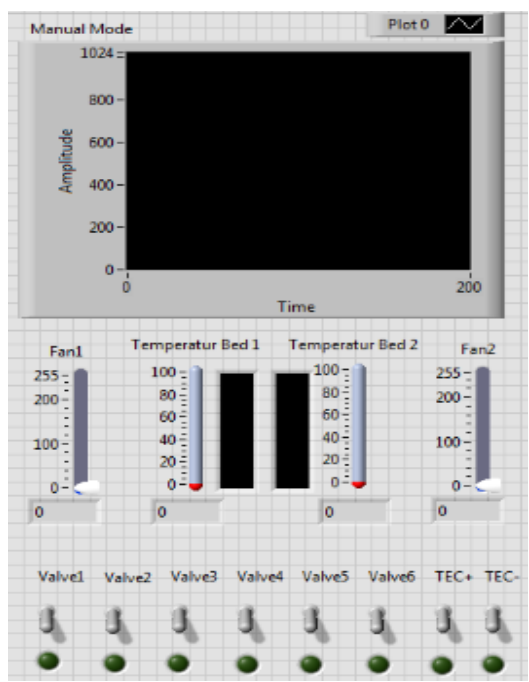

Gambar 13: tampilan mode manual

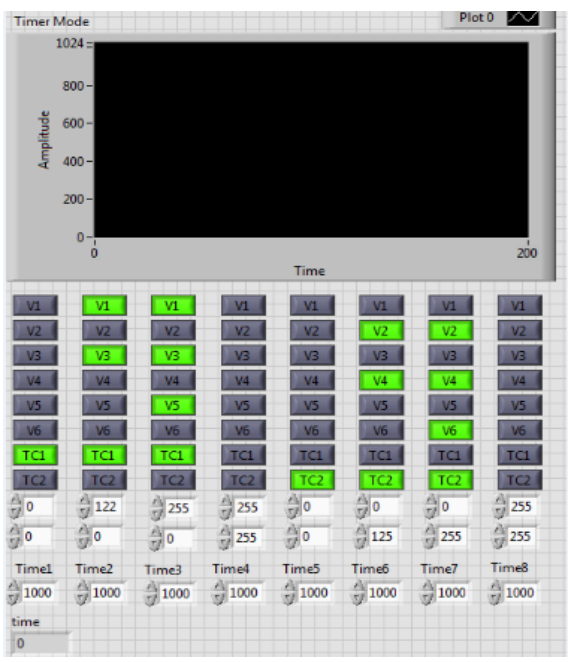

Gambar 14: tampilan mode timer

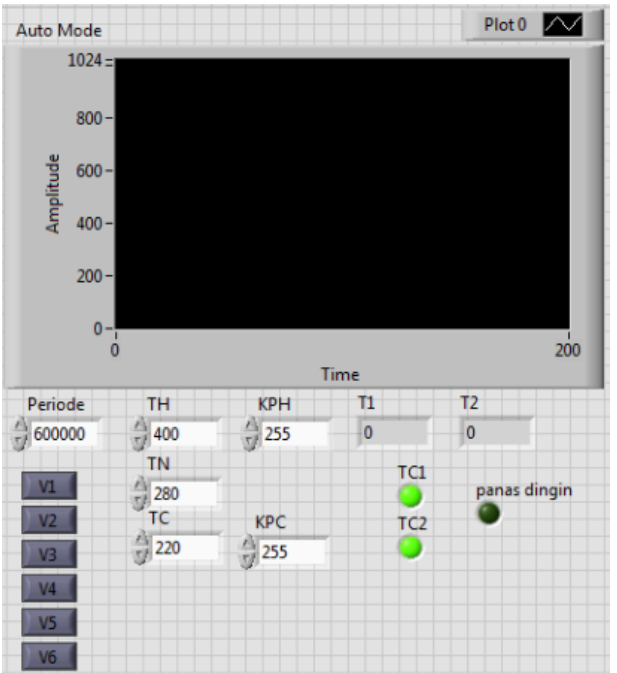

Gambar 15: tampilan mode auto 


\section{Kesimpulan}

1. Modul kontrol simulator refrigerasi adsorpsi telah dibuat dengan menggunakan platform kontroller arduino yang terintergrasi dengan perangkat lunak labview.

2. Modul kontrol simulator refrigerasi adsorpsi mampu mensimulasikan pengaturan temperatur panas dan dingin bed adsorpsi secara bergantian serta mampu mengatur arah aliran refrigeran melalui buka-tutup katup selenoid secara manual, timer, maupun automatis.

3. Pengaturan temperatur yang digunakan merupakan pengaturan on/off TEC dan pengaturan proporsional kipas pendingin serta mampu mengatur temperatur kedua bed adsorpsi dalam rentang $27-60^{\circ} \mathrm{C}$ untuk sisi panas dan $16-27^{\circ} \mathrm{C}$ untuk sisi dingin.

4. Penggunaan TEC sebagai sumber panas dapat membuat simulator mesin refrigerasi adsorpsi lebih efektif karena TEC dapat memanaskan dan mendinginkan bed adsorpsi secara bersamaan.

\section{Nomenklatur}

$\begin{array}{rll}\alpha & =\text { Koefisien Seebeck } & (\mathrm{V} / \mathrm{K}) \\ \rho & =\text { Masa jenis fluida } & \left(\mathrm{kg} / \mathrm{m}^{3}\right) \\ \mu & =\text { Viskositas dinamik } & (\mathrm{kg} / \mathrm{m} \cdot \mathrm{s}) \\ \mathrm{A} & =\text { Luas permukaan } & \left(\mathrm{m}^{2}\right) \\ C_{f} & =\text { Faktor bentuk } & \\ \mathrm{G} & =\text { Faktor geometri TEC } & (\mathrm{m}) \\ h & =\text { Koefisien konveksi } & \left(\mathrm{W} / \mathrm{m}^{2} \cdot \mathrm{K}\right) \\ I & =\text { Arus listrik } & (\mathrm{Amp}) \\ k & =\text { konduktifitas termal } & (\mathrm{W} / \mathrm{m} \cdot \mathrm{K}) \\ \mathrm{L} & =\text { Panjang batang } & (\mathrm{m})\end{array}$

$\begin{array}{llll}\mathrm{N} & = & \text { Jumlah pasang TEC } & \\ \mathrm{p} & = & \text { Hambatan dalam TEC } & (\Omega) \\ \mathrm{Pr} & = & \text { konstanta Prantle } & \\ Q_{c} & = & \text { Kalor pada sisi dingin } & \text { (Joule) } \\ Q_{c d} & = & \text { Kolor akibat konduksi } & \text { (Joule) } \\ Q_{j} & = & \text { Kalor joule } & \text { (Joule) } \\ & & & \\ Q_{s b} & = & \text { Kalor efek seebeck } & (\text { Joule) } \\ \mathrm{Re} & = & \text { Bilangan Reynold } & \\ T_{c} & = & \text { Temperatur sisi dingin } & \left({ }^{\circ} \mathrm{C}\right) \\ T_{h} & = & \text { Temperatur sisi panas } & \left({ }^{\circ} \mathrm{C}\right) \\ \Delta T & = & \text { Selisih temperatur } & \left({ }^{\circ} \mathrm{C}\right) \\ u & = & \text { Kecepatan aliran } & (\mathrm{m} / \mathrm{s}) \\ & & \end{array}$

\section{Daftar Pustaka}

[1] Dwi M. Purnomo Jati. "Perancangan, Pembuatan, dan Pengujian Sistem Refrigerasi Adsorpsi Kontinyu Bertekanan Kerja Positif", Skripsi, Teknik Mesin ITB , 2014.

[2] T.H. Chua, A. Chakraborty, X.L. Wang, "An Adsorption Chiller Driven by Thermoelectricity", Proceeding of International Refrigeration and Air Conditioning Conference, p. 677, 2004.

[3] Terry M. Tritt, dan Subramanian, "Thermoelectric Materials, Phenomena, and Applications", MRS Bulletin Volume 31, 2006.

[4] D. Artanto, "Interaksi Arduino dan Labview", Elex Media Koputindo, Jakarta, 2012.

[5] C. Alexander dan M. Sadiku, “ Fundamental of Electric Circuits", McGraw-Hill, Ed 4, New York, 2009.

[6] C.S. Rangan, G.R. Sarma, dan V. Mani, "Instrumentation Device and Systems", Tata McGraw-Hill, New Delhi, 1992.

[7] Frank P. Incropera , "Introduction to Heat Transfer”, John Welly \& Sons,Ed 5, 2007. 